\title{
REVENUE MODEL DAN CONDITIONAL REVENUE MODEL UNTUK MENDETEKSI MANAJEMEN LABA
}

\author{
Heni Yusnita \\ Program Studi Akuntansi, Fakultas Ekonomi Universitas Krisnadwipayana \\ Kampus Unkris Jatiwaringin \\ email : hyusnita@gmail.com
}

\begin{abstract}
Earnings management is a management action to manage the profitability of a company. The purpose of this study is to indicate the accrual earning management using revenue model and conditional revenue model. This study adopts the research conducted by Stubben (2010) where there are two measurement models to detect the presence of accrual earnings management. Object of this research is the companies listed in Indonesia Stock Exchange. The technique of data analysis is descriptive statistics to determine the residual value in each companies. These results prove that the revenue model is able to indicate the companies 34 of the total 38 in the manufacturing companies indicated accrual earnings management. Conditional revenue model is able to indicate the companies 36 of the total 38 in the manufacturing companies indicated accrual earnings management.
\end{abstract}

Keywords: Accrual earnings management, revenue model,

\section{PENDAHULUAN}

\section{conditional revenue model}

PSAK No. 1 tahun 2017 mengenai laporan keuangan bertujuan memberikan informasi mengenai posisi keuangan, kinerja keuangan dan arus kas entitas yang berguna bagi user dalam pengambilan keputusan. Informasi yang terkandung dalam laporan keuangan hendaknya harus relevan dan reliabel agar tidak menyesatkan para pengguna laporan keuangan. Sayangnya tidak semua perusahaan bersikap jujur dalam memberikan informasi perusahaannya disebabkan karena tuntutan pada manajemen untuk menunjukkan kinerja yang baik. Kinerja perusahaan tergambar dalam laporan keuangan. Stakeholder maupun shareholder mengukur prestasi manajemen dari tingkat laba yang dicapai. Semakin tinggi laba yang dicapai maka semakin baik penilaian prestasi terhadap manajemen. Jika dalam suatu periode tingkat laba yang diharapkan tidak tercapai maka timbullah praktek-praktek manajemen laba oleh pihak manajemen.

Manajemen laba merupakan sebuah fenomena dimana laporan keuangan tidak lagi memiliki kualitas yang baik karena tidak menggambarkan kondisi perusahaan sebenarnya. Hal ini dibuktikan dengan adanya beberapa praktik manajemen laba, salah satunya terjadi pada perusahaan besar "Toshiba" di jepang yang melakukan praktek ini dengan cara melebih lebihkan keuntungan sampai US\$12 miliar dolar dalam beberapa tahun (reuters) 3 September 2015.

Salah satu bentuk dari manajemen laba adalah manajemen laba akrual yang merupakan suatu bentuk perekayasaan laba perusahaan agar terlihat baik dalam persepsi investor melalui aktivitas akrual. Pemicu dari praktik manajemen laba karena pihak penanam modal maupun calon penanam modal hanya melihat dari laba yang dihasilkan tanpa menganalisa terlebih dahulu darimana laba tersebut didapatkan. Laba juga dipergunakan oleh stakeholders untuk mengevaluasi kinerja manajemen dan kinerja perusahaan. Selain itu manajemen laba juga timbul karena adanya konflik agency. Dimana Pemilik perusahaan menginginkan pengembalian modal yang telah ditanamkan yang dicerminkan dengan adanya peningkatan laba. Sedangkan pihak manajemen 
menginginkan insentif yang meningkat dan penilaian kinerja yang baik yang ditunjukkan dengan laba yang meningkat.

Manajemen laba terbagi dalam tiga kategori yaitu akuntansi yang curang (fraudulent accounting), manajemen laba akrual (accruals earnings management dan manajemen laba riil (real earnings management), (Gunny,2005). Akuntansi yang curang (fraudulent accounting) merupakan aktivitas akuntansi yang menyalahi General Accepted Accounting Principles (GAAP), manajemen laba akrual (accruals earnings management) meliputi aneka pilihan aktivitas akrual dalam GAAP yang menutupi kinerja perusahaan dan manajemen laba riil (real earnings management) manipulasi yang dilakukan manajemen melalui aktivitas perusahaan sehari hari selama periode akuntansi.

Pernyataan Standar Akuntansi

Keuangan No. 1 yang mengharuskan penyusunan laporan keuangan selain arus kas menggunakan dasar akrual menjadi penyebab terjadinya manajemen laba. Pemilihan dasar akrual ini dianggap lebih adil dan rasional untuk mengungkapkan informasi keuangan perusahaan sesungguhnya, tetapi penggunaan dasar akrual ini juga memberikan dampak bebasnya manajemen untuk memilih metode akuntansi dengan syarat tidak menyalahi PSAK. Metode akrual yang terdapat pada Pernyataan Standar Akuntansi Keuangan (PSAK) memberikan kebebasan kepada manajer dalam mengambil keputusan akuntansi yang akan memberi dampak pada pendapatan yang disajikan. Dalam hal ini pendapatan dapat dimanipulasi melalui discretionary accruals (Gumanti,2000).

Laba ekonomi merupakan selisih antara pendapatan dan beban (Ghozali dan Chariri, 2007). Oleh sebab itu target utama dari manajemen laba adalah pendapatan dan . Kebijakan yang dapat dilakukan manajemen dalam praktek manajemen laba adalah dengan cara merubah pengakuan pendapatan. Ada dua kemungkinan yang dapat dilakukan pada pendapatan. Pertama menurunkan pendapatan dengan menunda pengakuan atau pencatatan pendapatan yang menyebabkan menurunnya angka laba. Atau kedua, menaikkan pendapatan dengan mengakui pendapatan secara lebih awal sehingga menaikkan laba.

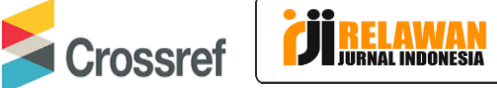

Begitupula dengan beban. Beban dapat diturunkan atau dinaikkan dengan mengandalkan biaya diskresi (Roychowdhury, 2006).

Seiring semakin maraknya praktik manajemen laba berkembang pula modelmodel pendeteksiaan yang digunakan dalam riset empiris. Model-model tersebut diantaranya adalah Modified Jones Model (1995), Kasznik Model (1999), Performance Matched Discretionary Accruals Model yang dikembangkan oleh Kothari dkk (2005) dan Discretionary Revenue Model yang dikembangkan oleh Stubben (2010)

\section{TINJAUAN PUSTAKA}

\section{Teori Keagenan (Agency Theory)}

Di dalam perusahaan yang semakin berkembang, perbedaan tujuan antara pemilik dan manajemen merupakan sesuatu yang tidak dapat dihindari. Adanya perbedaan antara pemilik sebagai prinsipal dan manajer sebagai agen yang menjalankan perusahaan akan menimbulkan konflik agensi dimana masingmasing pihak akan selalu berusaha untuk memaksimalkan fungsi utilitas yang dimilikinya. Jensen \& Meckling (1976) mendefinisikan hubungan keagenan sebagai kontrak dimana principal menyewa agent untuk melakukan beberapa jasa.

Konflik keagenan yang mengarah pada tindakan manajer yang opportunistic inilah yang akan berdampak pada hasil dari kualitas laba perusahaan. Pihak-pihak yang menggunakan informasi laba tentunya akan merasa dirugikan karena laba yang bersifat oportunis, itu berarti laba yang dilaporkan memiliki kualitas yang tidak bagus dan tidak mencerminkan informasi perusahaan yang sebenarnya. Bagi investor maupun perusahaan sangat dirugikan dengan kualitas laba yang rendah ini. Bagi pihak investor sudah jelas adanya asymetri informasi sedangkan bagi perusahaan terkait dengan nilai perusahaan jangka panjang yang tercermin dalam transaksi harga saham.

\section{Teori Sinyal (Signalling Theory)}

Perusahaan - perusahaan kadangkala dihadapkan kepada perbedaan kualitas antar perusahaan, seperti kualitas strategi pasar, sumber daya, informasi, dan juga kualitas pelaporan keuangan. Untuk menyampaikan 
adanya perbedaan tersebut, investor harus diberikan sinyal oleh perusahaan.

Signalling Theory menjadi dasar bagi manajer dalam memilih berbagai cara untuk mengkomunikasikan kualitas perusahaan. Signalling Theory mengelompokkan sinyal dalam dua kelompok besar yaitu sinyal secara langsung dan sinyal secara tidak langsung. Sinyal secara langsung tercermin dalam pengungkapan laporan keuangan perusahaan. Sinyal secara tidak langsung diantaranya terkait dengan kualitas, audit jumlah ekuitas yang dipertahankan, kebijakan deviden, struktur modal, publikasi peramalan perusahaan dan pemilihan kebijakan akuntansi.

\section{Manajemen Laba}

Scott (2006) mendefinisikan manajemen laba sebagai cara laba yang disajikan yang bertujuan agar utilitas manajemen dan nilai pasar ditingkatkan menggunakan pemilihan set kebijakan prosedur akuntansi yang dilakukan oleh manajemen. Terdapat dua sudut pandang untuk mengerti manajemen laba yang dilakukan manajer perusahaan: pertama, Manajemen laba bertujuan agar utilitas manajemen dimaksimalkan (opportunistic behavior). Kedua, bertujuan untuk memberikan keuntungan pada semua pihak yang terikat dalam kontrak (efficient contracting).

Watts, Zimmerman 1986 dan Pramudji, Trihartati, 2010 ) menyatakan bahwa motivasi manajemen laba antara lain : Debt (equity) hypothesis, Bonus plan hypothesis, dan Political cost hypothesis. Praktik Manajemen Laba (Earnings management) yang sering kali dilakukan perusahaan. Menurut Scott (2007) terdapat empat pola manajemen laba yaitu: a) Taking a bath adalah membuat laba perusahaan menjadi sangat ekstrim rendah (bahkan rugi) pada periode berjalan atau sangat ekstrim tinggi dibandingkan dengan laba pada periode sesudahnya atau sebelumnya. b) Income minimization adalah membuat laba yang disajikan pada periode berjalan lebih rendah daripada laba sesungguhnya. c) Maksimisasi laba (income maximization) adalah membuat laba yang disajikan pada periode berjalan lebih tinggi daripada laba sesungguhnya d) Income smoothing atau perataan laba merupakan manajemen laba yang dilakukan dengan cara membuat laba akuntansi relative konsisten (rata atau smooth) dari periode ke periode.

\section{Model Pendeteksian Manajemen Laba}

Model pendeteksian manajemen laba merupakan teknik yang dipakai dalam pengukuran manajemen laba di perusahaan. Seiring dengan perkembangan studi mengenai manajemen laba, bermunculan juga modelmodel untuk mencari proksi yang tepat dalam mendeteksi manajemen laba. Perkembangan model pendeteksian ini sampai dengan sekarang dapat dikategorikan menjadi dua model yaitu accrual model dan revenue model.

Accrual model menggunakan asumsi bahwa timbulnya non-discretionary berasal dari total accruals. Reveue model menitikberatkan pada pendapatan yang memiliki hubungan secara langsung dengan piutang. Revenue model dikembangkan oleh Stubben (2010) dengan mengembangkan dua formula yaitu revenue model dan conditional revenue model.

\section{Discretionary Revemue Model (2010)}

Berdasarkan ketidak puasan terhadap alat pengukuran manajemen laba sebelumnya. Pada tahun 2010 Stubben memperkenalkan Discretionary Revenue Model. Ada dua formula dalam discretionary revenue model yang dijadikan sebagai alat pengukuran manajemen laba. Pertama adalah revenue model, model ini menitikberatkan pada pendapatan yang memiliki hubungan secara langsung dengan piutang. Kedua yaitu conditional revenue model, model ini dikembangkan kembali dengan adanya penambahan ukuran perusahaan (size), umur perusahaan (age), dan margin kotor (GRM) yang diduga dapat digunakan dalam mendeteksi manajemen laba akrual mengenai pemberian kredit yang berhubungan dengan piutang. Ukuran perusahaan (firm size) merupakan proksi dari kekuatan finasial. Umur perusahaan merupakan proksi untuk tahap perusahaan dalam siklus bisnis. Sebagai proksi dari kinerja operasional dari perbandingan perusahaan dengan perusahaan kompetitor, digunakan gross margin.

Revenue Model menggunakan pendapatan perkuartalan yang diproksikan dengan piutang pertahun dengan anggapan bahwa apabila pendapatan perkuartal mampu menjelaskan piutang dengan baik, maka tidak akan terindikasi manajemen laba.

Revenue Model, Stubben (2010:701): $\Delta$ ARit $=\alpha+\beta 1 \Delta$ R1_3it $+\beta 2 \Delta$ R4it + eit 
di mana:

AR : Piutang pada kuartal ke empat

R1_3 : Pendapatan dalam tiga kuartal pertama

R4 : Pendapatan dikuartal keempat.

$\varepsilon \quad$ : error

Conditional Revenue Model, Stubben (2010:701):

$\Delta$ ARit $=\alpha+\beta 1 \Delta$ Rit $+\beta 2 \Delta$ Rit $\times$ SIZE + $\beta 3 \Delta$ Rit $\times$ AGEit $+\beta 4 \Delta$ Rit x AGE_SQit + $\beta 5 \Delta$ Rit x GRR_Pit + $\beta 6 \Delta$ Rit x GRR_Nit + $\beta 7 \Delta$ Rit x GRMit + $\overline{\beta 8} \Delta$ Rit x GRM_SQit + git

di mana:

AR : Piutang akhir tahun

R1_3 : Pendapatan pada kuartal ke-3

R4 : Pendapatan pada kuartal ke-4

SIZE : Natural log dari total aset akhir tahun AGE : Umur perusahaan (tahun)

GRM : Margin kotor yang disesuaikan pada akhir tahun fiskal

SQ : Kuadrat dari variabel

$\mathrm{E}$ : error

Pengklasifikasian nilai manajemen laba merujuk pada penelitian Roychowdurry yang memiliki konsep yang sama dalam perhitungan nilai manajemen laba yang dilakukan Stubben (2010) dimana $-0,075$ sampai dengan 0,075 dinyatakan tidak terindikasi manajemen laba akrual karena mendekati angka 0 .

\section{KERANGKA PENELITIAN}

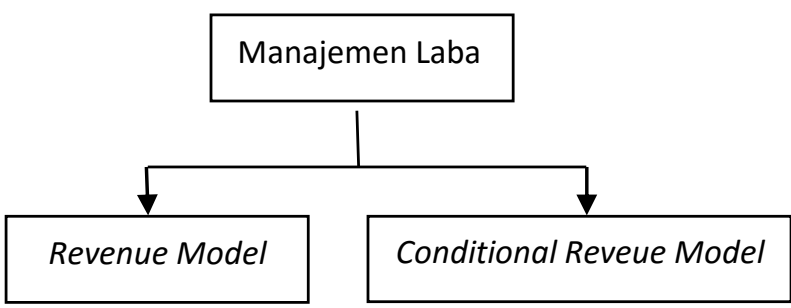

\section{METODE PENELITIAN}

\section{Rancangan Penelitian}

Penelitian ini merupakan penelitian kualitatif deskriptif yaitu dengan cara menganalisis dan mendeskripsikan hasil dari perhitungan manajemen laba akrual dengan pendekatan reveue model dan conditional revenue model. Data yang dipergunakan adalah data sekunder

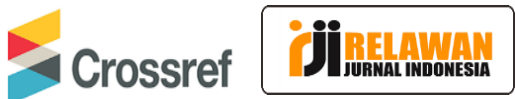

berupa laporan keuangan perusahaan manufaktur tahun 2015 dan 2016 yang didapat dari web Bursa Efek Indonesia (idx.co.id).

HASIL DAN PEMBAHASAN

a. Revenue Model

Tabel 1

Perubahan Manajemen Laba Akrual Dengan Revenue Model

\begin{tabular}{|c|c|c|c|}
\hline KODE & $\begin{array}{c}\text { Tahun } \\
\mathbf{2 0 1 5}\end{array}$ & $\begin{array}{c}\text { Tahun } \\
\mathbf{2 0 1 6}\end{array}$ & Mean \\
\hline APLN & $-0,201$ & $-0,064$ & $-0,133$ \\
\hline ASRI & 0,270 & 0,254 & 0,262 \\
\hline BAPA & 0,565 & $-0,163$ & 0,201 \\
\hline BEST & 1,052 & 1,040 & 1,046 \\
\hline BIPP & $-0,215$ & 0,333 & 0,059 \\
\hline BKDP & $-9,208$ & $-0,829$ & $-5,018$ \\
\hline BKSL & 0,464 & $-0,119$ & 0,172 \\
\hline BSDE & 0,450 & 0,910 & 0,680 \\
\hline COWL & 0,347 & 0,056 & 0,201 \\
\hline CTRA & 0,290 & $-0,119$ & 0,086 \\
\hline DART & 0,726 & $-0,994$ & $-0,134$ \\
\hline DILD & 0,534 & $-0,382$ & 0,076 \\
\hline DUTI & 0,222 & 0,119 & 0,170 \\
\hline ELTY & 0,008 & $-0,287$ & $-0,140$ \\
\hline EMDE & $-0,282$ & 0,141 & $-0,070$ \\
\hline FMII & $-0,497$ & $-0,704$ & $-0,600$ \\
\hline GAMA & 0,346 & $-0,084$ & 0,131 \\
\hline GMTD & 0,626 & $-0,867$ & $-0,120$ \\
\hline GPRA & 0,355 & $-0,146$ & 0,105 \\
\hline GWSA & 0,624 & 0,090 & 0,357 \\
\hline JRPT & 0,490 & $-0,156$ & 0,167 \\
\hline KIJA & 0,339 & 0,664 & 0,501 \\
\hline LAMI & 0,130 & $-0,554$ & $-0,212$ \\
\hline LPCK & 0,735 & $-0,206$ & 0,264 \\
\hline LPKR & 0,840 & 0,050 & 0,445 \\
\hline MDLN & 0,723 & 0,225 & 0,474 \\
\hline MKPI & $-1,010$ & 0,610 & $-0,200$ \\
\hline MTLA & $-0,162$ & $-0,333$ & $-0,248$ \\
\hline MTSM & 0,519 & 1,320 & 0,920 \\
\hline NIRO & $-0,090$ & 0,520 & 0,215 \\
\hline OMRE & $-0,217$ & $-0,601$ & $-0,409$ \\
\hline PLIN & 0,134 & $-0,125$ & 0,005 \\
\hline PWON & 0,227 & $-0,476$ & $-0,124$ \\
\hline RDTX & $-0,172$ & $-0,223$ & $-0,198$ \\
\hline RODA & 0,839 & $-0,673$ & 0,083 \\
\hline & & & \\
\hline
\end{tabular}


Printed ISSN 2406-7415

e-ISSN 2655-9919

Jurnal Akuntansi \& Bisnis Krisnadwipayana

Vol. 6 No. 2 (Mei - Agustus) 2019

\begin{tabular}{|c|c|r|c|}
\hline SCBD & $-0,363$ & $-1,035$ & $-0,699$ \\
\hline SMDM & $-0,262$ & 0,250 & $-0,006$ \\
\hline $\begin{array}{c}\text { SMRA } \\
\text { Sumber : data diolah penulis (2019) }\end{array}$ & 0,823 & 2,558 & 1,690 \\
\hline
\end{tabular}

Gambar 1

Perubahan Manajemen Laba Akrual dengan Revenue Model

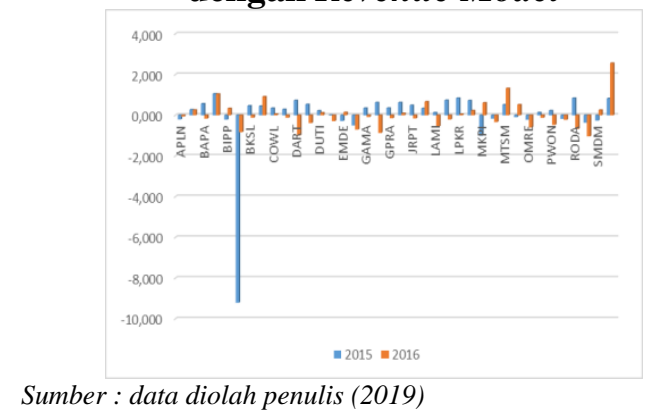

Dari tabel 1 yang diperjelas dengan gambar 1 dapat dilihat bahwa berdasarkan rata-rata nilai residual hampir seluruh perusahaan sampel melakukan manajemen laba akrual. Dari 38 sampel perusahaan, yang terindikasi melakukan manajemen laba sebanyak 34 perusahaan. 4 Perusahaan yang tidak terindikasi melakukan manajemen laba adalah BIPP, EMDE, PLIN dan SMDM. Praktek manajemen laba akrual tertinggi dilakukan oleh BKDP dimana mean nilai residual yang menandakan nilai manajemen laba adalah 5,018. Sedangkan praktek manajemen laba terendah dilakukan oleh DILD yang memiliki nilai mean residual 0,076 yang berarti nilai residualnya mendekati 0 .

Jika dilihat dari tahun penelitian, kegiatan praktek manajemen laba pada tahun 2015 tertinggi dilakukan oleh BKDP , dimana nilai residualnya mencapai $-9,208$. Sedangkan praktek manajemen laba terendah dilakukan oleh NIRO, dimana nilai residualnya $-0,90$. Pada tahun 2016 manajemen laba tertinggi masih dilakukan oleh BKDP dengan nilai residual sebesar $-0,829$. Sedangkan praktek terendah dilakukan oleh GAMA dengan nilai residual $-0,084$.

Perusahaan sampel yang pada tahun 2015 tidak terindikasi melakukan praktek manajemen laba tetapi kemudian terindikasi melakukan di tahun 2016 yaitu ELTY, dimana nilai residual pada tahun 2015 adalah 0,008 sedangkan di tahun 2016 nilainya -0,287. Sedangkan perusahaan sampel yang terindikasi melakukan manajemen laba pada tahun 2015 tetapi pada tahun 2016 tidak

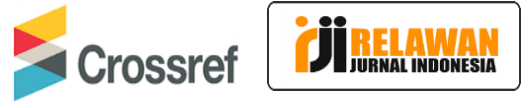

terindikasi melakukan adalah LPKR dan APLN dengan masing-masing nilai residualnya 0,050 dan $-0,064$ ditahun 2016 yang tahun sebelumnya yaitu 2015 memiliki nilai residual 0,840 dan $-0,201$.

Tabel -2

Kelompok Nilai Manajemen Laba Akrual dengan Revenue Model

\begin{tabular}{|c|l|l|c|c|c|}
\hline \multirow{2}{*}{ No } & \multirow{2}{*}{ Klasifikasi } & \multirow{2}{*}{ Status } & \multicolumn{2}{|c|}{ Tahun } & \multirow{2}{*}{ Total } \\
\cline { 3 - 5 } & & & $\mathbf{2 0 1 5}$ & $\mathbf{2 0 1 6}$ & \\
\hline 1 & $<-0,075$ & Terindikasi MLA & 12 & 21 & 33 \\
\hline 2 & $-0,075 \mathrm{~s} / \mathrm{d} 0,075$ & Tidak Terindikasi MLA & 1 & 2 & 3 \\
\hline 3 & $>0,075$ & Terindikasi MLA & 25 & 15 & 40 \\
\hline & & Total & 38 & 38 & 76 \\
\hline \multicolumn{2}{|l}{} \\
\multicolumn{2}{|l}{ Sumber $:$ data diolah penulis (2019) }
\end{tabular}

Berdasarkan pada Tabel 2 dapat di lihat bahwa jumlah perusahaan yang terindikasi manajemen laba akrual pada tahun 2015 sebanyak 37 perusahaan dari total 38 perusahaan atau 97,4\%. Kemudian untuk tahun 2016 yang terindikasi manajemen laba akrual sebanyak 36 perusahaan atau $94,7 \%$. Perusahaan yang tidak terindikasi melakukan praktek manajemen laba di tahun 2015 berjumlah 1 perusahaan (ELTY) atau 2,6\%. Dan pada tahun 2016 berjumlah 2 perusahaan (LPKR dan APLN) atau 5,3\%. Persentase perusahaan yang terindikasi melakukan praktek manajemen laba lebih besar dari persentase perusahaan yang tidak terindikasi melakukan praktek manajemen laba. Sehingga dapat disimpulkan bahwa dengan menggunakan revenue model sebagian besar perusahaan manufaktur yang dijadikan sampel terindikasi melakukan praktek manajemen laba.

\section{b. Conditional Revenue Model}

Tabel 3

Perubahan Manajemen Laba Akrual

Dengan Conditional Revenue Model

\begin{tabular}{|l|c|c|c|}
\hline KODE & $\begin{array}{c}\text { Tahun } \\
\mathbf{2 0 1 5}\end{array}$ & $\begin{array}{c}\text { Tahun } \\
\mathbf{2 0 1 6}\end{array}$ & Mean \\
\hline APLN & 0,924 & $-0,194$ & 0,365 \\
\hline ASRI & $-1,003$ & 0,258 & $-0,373$ \\
\hline BAPA & $-0,079$ & $-0,243$ & $-0,161$ \\
\hline BEST & 0,556 & 1,044 & 0,800 \\
\hline BIPP & $-0,517$ & 0,208 & $-0,155$ \\
\hline BKDP & $-2,117$ & $-0,589$ & $-1,353$ \\
\hline BKSL & 1,175 & 0,146 & 0,660 \\
\hline BSDE & 0,344 & 1,588 & 0,966 \\
\hline COWL & 0,027 & 0,013 & 0,020 \\
\hline CTRA & $-0,056$ & $-0,046$ & $-0,051$ \\
\hline
\end{tabular}


Printed ISSN 2406-7415

e-ISSN 2655-9919

Jurnal Akuntansi \& Bisnis Krisnadwipayana

Vol. 6 No. 2 (Mei - Agustus) 2019

\begin{tabular}{|c|c|c|c|}
\hline DART & 1,450 & $-0,430$ & 0,510 \\
\hline DILD & $-0,045$ & $-0,499$ & $-0,272$ \\
\hline DUTI & 0,353 & 0,113 & 0,233 \\
\hline ELTY & $-0,059$ & $-0,164$ & $-0,112$ \\
\hline EMDE & $-0,487$ & 0,133 & $-0,177$ \\
\hline FMII & $-0,719$ & $-0,704$ & $-0,711$ \\
\hline GAMA & 1,513 & $-0,623$ & 0,445 \\
\hline GMTD & 0,380 & $-0,933$ & $-0,276$ \\
\hline GPRA & 0,498 & $-0,279$ & 0,110 \\
\hline GWSA & $-0,965$ & $-0,036$ & $-0,501$ \\
\hline JRPT & $-0,071$ & $-0,360$ & $-0,215$ \\
\hline KIJA & $-0,076$ & 0,721 & 0,322 \\
\hline LAMI & $-0,414$ & $-0,207$ & $-0,310$ \\
\hline LPCK & 0,533 & 0,027 & 0,280 \\
\hline LPKR & 0,770 & $-0,161$ & 0,304 \\
\hline MDLN & 0,715 & 0,271 & 0,493 \\
\hline MKPI & 0,871 & $-0,139$ & 0,366 \\
\hline MTLA & $-0,478$ & $-0,421$ & $-0,449$ \\
\hline MTSM & $-2,003$ & 1,183 & $-0,410$ \\
\hline NIRO & $-0,221$ & 0,694 & 0,236 \\
\hline OMRE & $-0,500$ & $-0,636$ & $-0,568$ \\
\hline PLIN & $-0,023$ & $-0,229$ & $-0,126$ \\
\hline PWON & 0,011 & $-0,592$ & $-0,291$ \\
\hline RDTX & $-0,264$ & $-0,337$ & $-0,301$ \\
\hline RODA & 0,658 & $-0,201$ & 0,229 \\
\hline SCBD & $-0,524$ & $-1,145$ & $-0,834$ \\
\hline SMDM & $-0,688$ & 0,260 & $-0,214$ \\
\hline SMRA & 0,530 & 2,508 & 1,519 \\
\hline
\end{tabular}

Gambar 2

Perubahan Manajemen Laba Akrual dengan Conditional Revenue Model

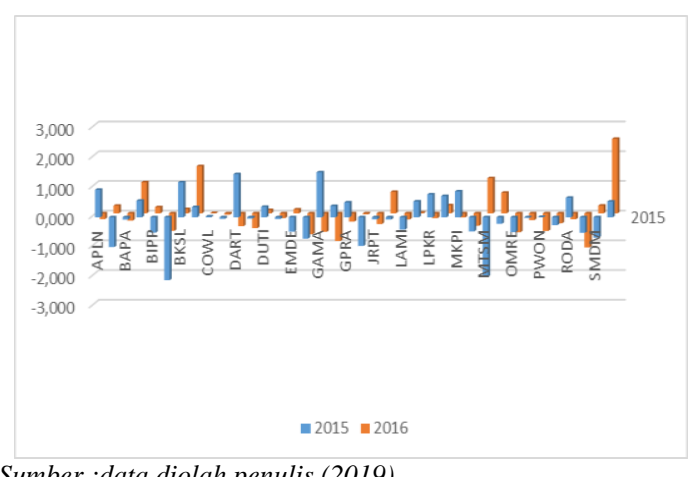

Sumber :data diolah penulis (2019)

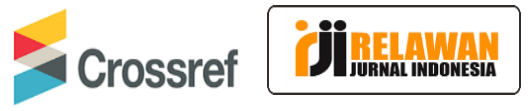

Dari tabel 3 dan gambar 2 dapat dilihat bahwa berdasarkan rata-rata nilai residual hampir seluruh perusahaan sampel melakukan manajemen laba akrual. Dari 38 sampel perusahaan, yang terindikasi melakukan manajemen laba sebanyak 36 perusahaan. 2 Perusahaan yang tidak terindikasi melakukan manajemen laba adalah COWL dan CTRA. Praktek manajemen laba akrual tertinggi dilakukan oleh SMRA dimana mean nilai residual yang menandakan nilai manajemen laba adalah 1,519. Sedangkan praktek manajemen laba terendah dilakukan oleh GPRA yang memiliki nilai mean residual 0,110 .

Jika dilihat dari tahun penelitian, kegiatan praktek manajemen laba pada tahun 2015 tertinggi dilakukan oleh BKDP , dimana nilai residualnya mencapai $-2,117$. Sedangkan praktek manajemen laba terendah dilakukan oleh KIJA, dimana nilai residualnya $-0,076$. Pada tahun 2016 manajemen laba tertinggi dilakukan oleh SMRA dengan nilai residual sebesar 2,508. Sedangkan praktek terendah dilakukan oleh DUTI dengan nilai residual 0,113 .

Perusahaan sampel yang pada tahun 2015 tidak terindikasi melakukan praktek manajemen laba tetapi kemudian terindikasi melakukan di tahun 2016 yaitu JRPT, DILD, ELTY, PLIN dan PWON. JRPT memiliki nilai residual pada tahun 2015 adalah $-0,071$ sedangkan di tahun 2016 nilai residualnya menjadi $-0,360$. DILD memiliki nilai residual pada tahun 2015 adalah $-0,045$ sedangkan di tahun 2016 nilai residualnya menjadi $-0,499$. ELTY memiliki nilai residual pada tahun 2015 adalah -0,059 sedangkan di tahun 2016 nilai residualnya menjadi $-0,164$. PLIN memiliki nilai residual pada tahun 2015 adalah $-0,023$ sedangkan di tahun 2016 nilai residualnya menjadi -0,229. PWON memiliki nilai residual pada tahun 2015 adalah 0,011 sedangkan di tahun 2016 nilai residualnya menjadi $-0,592$. Sedangkan perusahaan sampel yang terindikasi melakukan manajemen laba pada tahun 2015 tetapi pada tahun 2016 tidak terindikasi melakukan adalah GWSA dengan masing-masing nilai residualnya yaitu $-0,036$ dan -0,501. LPCK dengan masing-masing nilai residualnya yaitu 0,533 dan 0,027 .

\section{Tabel 3}




\section{Kelompok Nilai Manajemen Laba Akrual} dengan Conditional Revenue Model

\begin{tabular}{|c|l|l|c|c|c|}
\hline \multirow{2}{*}{ No } & \multirow{2}{*}{ Klasifikasi } & \multirow{2}{*}{ Status } & \multicolumn{2}{|c|}{ Tahun } & \multirow{2}{*}{ Total } \\
\cline { 4 - 5 } & & & $\mathbf{2 0 1 5}$ & $\mathbf{2 0 1 6}$ & \\
\hline 1 & $<-0,075$ & Terindikasi MLA & 16 & 21 & 37 \\
\hline 2 & $-0,075 \mathrm{~s} / \mathrm{d} 0,075$ & Tidak Terindikasi MLA & 7 & 4 & 11 \\
\hline 3 & $>0,075$ & Terindikasi MLA & 15 & 13 & 28 \\
\hline \multicolumn{2}{|l|}{} & Total & 38 & 38 & 76 \\
\hline
\end{tabular}

Berdasarkan pada Tabel 3 dapat di lihat bahwa jumlah perusahaan yang terindikasi manajemen laba akrual pada tahun 2015 sebanyak 31 perusahaan dari total 38 perusahaan atau $81,6 \%$. Kemudian untuk tahun 2016 yang terindikasi manajemen laba akrual sebanyak 34 perusahaan atau $89,5 \%$. Sedangkan yang tidak terindikasi melakukan praktek manajemen laba pada tahun 2015 berjumlah 7 perusahaan atau hanya $18,4 \%$. Dan ditahun 2016 berjumlah 4 perusahaan atau $10,5 \%$. Persentase perusahaan yang terindikasi melakukan praktek manajemen laba lebih besar dari persentase perusahaan yang tidak terindikasi melakukan praktek manajemen laba. Sehingga dapat disimpulkan bahwa dengan menggunakan Conditional revenue model sebagian besar perusahaan manufaktur yang dijadikan sampel terindikasi melakukan praktek manajemen laba.

Dari analisis diatas secara umum memberikan bukti bahwa piutang dan pendapatan merupakan akun-akun yang dapat dijadikan sebagai alat pengukuran praktek manajemen laba, Stubben (2010). Hasil penelitian ini juga memperkuat hasil dari penelitian terdahulu dimana hampir sebagian besar model-model pengukuran manajemen laba menggunakan pendapatan dan piutang sebagai salah satu komponen perhitungannya.

\section{KESIMPULAN DAN SARAN}

Berdasarkan analisis menggunakan pengukuran Revenue Model , dari 38 sampel perusahaan yang terindikasi melakukan manajemen laba di tahun 2015-2016 dari ratarata residual perusahaan yang terindikasi melakukan manajemen laba menggunakan Revenue Modal sebanyak 34 perusahaan dan 36 perusahaan terindikasi melakukan manajemen laba menggunakan Conditional Revenue Model. Di tahun 2015 sebanyak 37 perusahaan terindikasi melakukan manajemen laba dan tahun 2016 sebanyak 36 perusahaan. Perusahaan yang tidak terindikasi melakukan

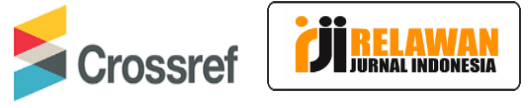

praktek manajemen laba di tahun 2015 berjumlah 1 yaitu ELTY. Dan tahun 2016 berjumlah 2 perusahaan yaitu LPKR dan APLN . Berdasarkan hasil pengukuran dapat disimpulkan bahwa dengan menggunakan Revenue Model sebagian besar perusahaan manufaktur terindikasi manajemen laba.

Berdasarkan analisis menggunakan pengukuran Conditional Revenue Model, dari 38 sampel perusahaan, jumlah perusahaan yang terindikasi melakukan praktek manajemen laba akrual pada tahun 2015 sebanyak 31 perusahaan. Kemudian untuk tahun 2016 yang terindikasi manajemen laba akrual sebanyak 34 perusahaan. Sedangkan yang tidak terindikasi melakukan praktek manajemen laba pada tahun 2015 berjumlah 7 perusahaan( COWL, CTRA, JRPT, DILD, ELTY, PLIN dan PWON ). Dan ditahun 2016 berjumlah 4 perusahaan (COWL, CTRA, LPCK dan GWSA). Berdasarkan hasil pengukuran dapat disimpulkan bahwa dengan menggunakan Conditional Revenue Model sebagian besar perusahaan manufaktur terindikasi manajemen laba.

\section{DAFTAR PUSTAKA}

Ahmar, N dan Wahyu S. (2014), Pengaruh Manajemen Laba Akrual dengan Pendekatan Revenue Discretionary Model terhadap Kinerja Perusahaan, Trikonomika, Volume 13 No. 1, Hal. 108-118

Brealey, Myres, dan Marcus. (2007), Dasardasar manajemen keuangan perusahaan, Edisi Kelima, Jakarta : Erlangga.

Cohen, D.A., A. Dey, dan T.Z. Lys. (2008), Real and accrual-based earnings management in the pre- and postSarbanes-Oxley periods. The Accounting Review, Vol. 83, No. 3: 757-787

Cohen, D.A. dan Paul, Z, (2008), AccrualBased and Real Earnings Management Activities around Seasoned Equity Offerings, Working Paper. Stern School of Business, New York University.

Denies, (2008), Eksistensi Earnings Manajemen dalam Hubungan AgenPrinsipal, Jurnal Pendidikan 
Akuntansi Indonesia, Vol. VI. No. 2 , Hal. $23-36$

Dechow, P.M., R.G. Sloan, dan A.P. Sweeney. (1995), Detecting earnings management, The Accounting Review, Vol. 70, No. 2: 193-225

Ghozali, I . (2006), Aplikasi Analisis

Multivariate dengan Program SPSS, Edisi ke-4, Semarang : Badan Penerbit Universitas Diponegoro

Gultom dan Ahmar. (2016), Model Manajemen Laba Stubben, Tata Kelola dan Nilai Perusahaam Industri Dasar Dan Kimia dI Indonesia, Prosiding Seminar INDOCOMPAC, Jakarta.

Gumanti, A. (2006), Manajemen Laba: Apa dan Mengapa, Kajian Akuntansi.Vol. 1, No. 1, Juni 2006, hlm 1-13

Gunny, K. (2005), What Are the Consequences of Real Earnings Management?, Working paper, Haas School of Business, University of California, Berkeley.

Ikatan Akuntan Indonesia. (2017), Standar Akuntansi Keuangan, Salemba Empat: Jakarta

Leuz, C., D. Nanda, dan P.D. Wysocki. (2003), Earnings management and investor protection: An international comparison, The Journal of Financial Economics, 69: 505-527

Roychowdhury, S. (2006). Earnings management hrough real activities manipulation. Journal of ccounting and Economics, 42: 335-370

Sahabu, Supardi. (2009). Manajemen Laba Melalui Akrual dan Manipulasi Aktivitas Nyata dan Pengaruhnya Terhadap Kinerja Jangka Panjang Perusahaan yang Melakukan Penawaran Right Issue. Tesis STIE YKPN

Sari dan Ahmar. (2014), Revenue Discretionary Model Pengukuran Manajemen Laba: Berdasarkan Sektor Industri Manufaktur di Bursa Efek Indonesia, Jurnal Akuntansi dan Keuangan, Vol. 16 no. 1

Stuben, S.R. (2010), Discretionary revenues as a measure of earnings management.
The Accounting Review, Vol. 67, No. 3: $546-562$.

Sugiri, (2005), Akuntansi Manajemen, Yogyakarta : BPFE

Sugiyono, (2008), Metode Penelitian Bisnis, Bandung: Alfabeta

Sulistyanto,S. (2008), Manajemen Laba Teori dan Model Empiris, Jakarta: Grasindo

Sulistiawan, dkk. (2011), Creative

Accounting, mengungkap Manajemen Laba dan Skandal Akuntansi, Salemba Empat:

Jakarta 
Printed ISSN 2406-7415

e-ISSN 2655-9919

Jurnal Akuntansi \& Bisnis Krisnadwipayana

Vol. 6 No. 2 (Mei - Agustus) 2019 